December - 2006

\title{
Editorial
}

\section{Environmental Scan: Results of the IRRODL User Survey}

\section{Terry Anderson}

First, I'd like to thank the 118 readers who completed our first IRRODL user survey. We have published a summary of the results here as feedback to the respondents and as guidelines for ourselves, our reviewers, and editors, as well as to others currently publishing Open Access Journals.

We are flattered by the results, which has rekindled our sense of 'mission' thanks to the many positive responses. In addition, we now have feedback to use to improve IRRODL.

We were slightly surprised to see that nearly 40 percent of the respondents are relatively new (less than one year reading of IRRODL), indicating a healthy growth in readership. Seventy percent were subscribers and the rest probably arrived at the website through recommendations or search engine referral. Only 17 percent of respondents used the RSS feature to remind them of new postings. RSS Feed's relatively low usage is understandable given the emerging nature of this push technology (which enables the RSS Feed users to receive only information that interests them - clearly a handy screening device given the amount of content published on the Internet daily!)

We were especially interested in the response to the addition of MP3 audio files affording ability to listen, in addition to reading, our articles. Only 31 percent of respondents felt that MP3 listening was important to them, but with the increasing use of podcasting and MP3 playback devices, we anticipate that interest will grow and continue to make the effort of converting content to audio format worthwhile. We were also pleased that only two readers felt we published too often; 75 felt we had the right number (about three issues per year), while 31 felt they wanted more!

A full 92 percent of respondents were satisfied with the breadth of coverage, 95 percent with the quality, and 94 percent with the currency of content published in IRRODL. Email push to subscribers was the most popular way (54\%) that readers found out about articles with 29 percent finding them through Google or other search engines. As expected, the Main Section scholarly peer reviewed articles were read more extensively than Research Reports, Book Reviews, or the Technical Evaluation Reports.

Readers indicated to us that they were most interested in research findings (81\%) with applied practice (88\%) and distance education theory at 62 percent of respondents. Topics of interest were diverse leading with distance education pedagogy (88\% of readers expressing interest), 
instructor development and support (70\%) and interest in qualitative studies (70\%) as compared to quantitative studies at (56\%). When queried about additional technologies that could be used to enhance IRRODL only threaded discussion (tried with little success in early issues) exceeding the response that no other technologies are needed.

Surprisingly 56 percent of respondents read the articles online with only 38 percent regularly printing the articles. Demographically, respondents were generally highly educated with graduate level education (Bachelor 8\%; Masters 45\%; Doctorate 36\%). Respondents came from every continent, except Antarctica. As expected the largest response was from North America (53\%) followed by Europe (18\%) and Asia (11\%).

Responses to the open-ended query of 'things liked most' were wide and tended to be complementary, with availability and open access being the single most popular response. There were also many suggestions for improvement including formatting and screen layout improvements (a new site layout is in design mode now). We also had suggestions for more (and less) coverage of particular regions. These opposing regional suggestions makes me think we have reached a typical Canadian compromise - one in which no one is satisfied!

To end on a positive note, the survey reaffirmed the value of IRRODL and provided us with concrete suggestions for improvement. Thank you to those who shared their comments and insights, your input and feedback is invaluable.

Now for an overview of this, our final issue for 2006!

\section{Overview: Volume 7, No. 3.}

In this issue, we bring you seven Main Section papers, which we hope you will enjoy and - more importantly - will use to inform your scholarly pursuits and practice. We also provide one Research Report and one Technical Evaluation report.

Our lead article is from Canada and entitled: Learners' Perspectives on what is Missing from Online Learning: Interpretations through the Community of Inquiry Framework. In this paper, Canadian scholars Emma Stodel, Terrie Lynn Thompson, and Colla MacDonald report on an inquiry (using a community of inquiry framework to interpret their results) on learners' perceptions of what is missing from online learning contexts. Conducted within a constructivist perspective, this paper reports on a qualitative study of ten who were asked about "what they missed most when learning online as compared to face-to-face learning?”

Next is a fascinating paper from Australia entitled: Designing Websites for Learning and Enjoyment: A study of museum experiences, by Aleck Lin and Shirley Gregor. In this paper, Drs. Lin and Gregor explore the world of online museums and their public/ pedagogical personas on the World Wide Web. Clearly, museums play an important role for enrichment to formal education as suggested by the authors. However, an ever growing contribution is the provision of both knowledge and community for lifelong learners spread through the Net.

Next we have a paper from The Netherlands entitled: Feedback Model to Support Designers of Blended Learning Courses, by Hans Hummel. Effective feedback has long been associated with all forms of quality education - including that delivered at a distance. Hummel reports on a pilot study that examined six-phases of a feedback model developed for blended learning courses. Research examining the usability and value of the model with practicing developers and teachers 
are outlined. While this research indicated that the overall quality of this feedback model to be sufficient, it was also reported that revisions are necessary before the model could be implemented in practice. We do need theorists and designers to develop new methods and models, but equally important are those testing and evolving them for efficacy in the field.

We return to Canada with a paper entitled: Partner Power: A study of two distance education consortia, by Anne Banks-Pidduck and Tom Carey. Distance and Open education systems seem likely candidates for partnerships in which collaborative input is used to create greater output than that possible by individual partners. Despite this potential advantage, most of us are as familiar with failed partnerships and collaborations that never "took off." In this study Pidduck and Carey examine the process by which two Canadian distance education consortia picked their partners. Considerations of compatibility, culture, status, and convenience prove to be as determinant factors as desire to work together. The two distance education consortia examined also reveals the complex nature of Canada as a highly heterogeneous nation state built on pluralist values.

Next we leap to India, one of the fastest developing countries with a wealth of distance education practice and tradition. The Study of the Factors Responsible for the Dropouts from the BSc Programme of Indira Gandhi National Open University, by Bharat Inder Fozdar, Lalita S. Kumar, and S. Kannan looks at the perennial issue of attrition in distance programming. Their study focuses on the particular challenges of science education, with the need for laboratory experiences (virtual or classroom based) that often create challenges for both educators and students. The study reveals several clusters of variables associated with dropout - many of which are familiar from the literature. However, the study uniquely views the importance science students place on non-institutional factors such as cost associated with travel and distance involved in attending face-to-face laboratory classes. The authors conclude with recommendations for IGNOU (and I assume many other distance education institutions) to enhance completion rates for students in science programming delivered at a distance.

Our sixth main article examines problem-based learning (PBL) supported through computer conferencing. The article, a Pilot Study of Problem Formulation and Resolution in an Online Problem-based Learning Course by Richard Kenny, Mark Bullen and Jay Loftus provides a strong rationale for the inclusion of PBL in online contexts - even when students do not meet face-to-face. Kenny and colleagues report on an exploratory study designed to investigate student problem formulation and resolution processes in an undergraduate Agricultural Sciences course. The authors used a content analysis instrument designed originally for face-to-face PBL to measure problem formulation and resolution (PFR) processes in online asynchronous discussions. While there is some evidence that these students do engage in problem formulation and resolution (consistent with the PBL processes and pedagogy), in this institutional context, PBL problems remained tied to marked assignment structure, which tended to restrict full development of PFR processes.

We wrap-up the Main Section of this issue with a paper from the Canary Islands entitled, Online Faculty Development and Assessment System (OFDAS), by Luis Viller and Olga Alegre. Using statistical analysis, the authors report on current 'best practices' of student online assessment, and a circular professional development model they developed (OFDAS). The OFDAS model designed to serve double duty as a faculty development tool and a classroom learning environment assessment - was used by two universities in the Canary Islands. Findings reported illustrate that the OFDAS helped faculty to reflect on their teaching practices, which were in turn guided by student feedback on their classroom experiences. Viller and Algre then go on to discuss implications of the process of online teaching and knowledge acquisition, to build a 
comprehensive view of faculty teaching attitudes and their relationship to student's perceptions of their classroom experience at these two Canarian universities.

\section{Research Notes and Technical Evaluation Report}

For the Research Notes we provide overviews of two emerging technologies by Master of Distance Education students at Athabasca University. The first is a personal account (in diary format) of Wendy Elliot's investigation of radio and podcasting for distance delivery. Though grounded in Canadian radio history, similar audio education has (and continues to) evolve in many countries. The Audiocast Diaries: Reflections on radio and podcasting for delivery of educational soap operas is a nice change of formatting pace for a scholarly journal, but I am sure you will both enjoy and learn from Wendy's diaries.

Our Technical Notes section contains a technical evaluation report by Steve Swettenham, who examines five open source RSS feed creation tools. The article ties back nicely into data collected from the IRRODL user survey outlined above. If you are not familiar with this important new technology and how you might be able to use it to your advantage, this Technical Report will be a good starting point.

Peace and Best Wishes to all our readers and their students!

\section{Terry Anderson}

December 19, 2006



